\title{
Three Views of a Secret: The "Mønsterlig"
}

\section{By TOM MUIR}

\begin{abstract}
In a world where English - and its attendant writing conventions - is the dominant language of research, it becomes increasingly important to explore academic patterns of writing and teaching, and their related etymologies. In particular, this article investigates the relationship between the Norwegian "mønster" and the English "monster", arguing that monsters allow us to make space for new kinds of writing, new languages of thought. Monstrosity, and monstrous patterns - meanings that are available in Norwegian rather than English - let slip alternative ways of thinking about teaching, writing and teaching writing. This is done through an exploration of the work of the literary critic Barbara Johnson, who gives us three uncanny topics prosopopoeia, monuments and repetition compulsion - that help us release the warnings (Latin: "monere") from mønstre (Norwegian: "patterns"). The article argues that prosopopoeia, monuments and repetition can help us to hear the monster within mønstrene (the patterns). At the same time, the paper seeks a critical self-awareness of its status as an English language text about a Norwegian word. Acknowledging that these conventions are themselves historical and cultural artefacts - are mønstre - the article therefore tries to interrupt and unravel itself in the hope of making space for alternative kinds of writing.
\end{abstract}

\section{KEYWORDS}

Monster studies; Barbara Johnson; Pedagogy; Academic Writing; The Uncanny; patterns

Tom Muir has a PhD in English Literature from Sussex University and currently teaches academic English for researchers at Oslo and Akershus University College in Norway. He is interested in the monstrous things that teaching pushes to its margins - ghosts, magic, telepathy, the occult. 


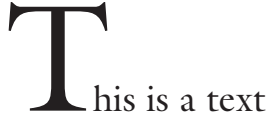
about patterns, repetition and teaching. It is also a text about flesh and stone, the animate and inanimate, the monument and the forgotten. It seeks to explore the Norwegian word "mønster" ("pattern") and its etymological connection with the English word "monster", and to think through the implications of this relationship. It does so by pursuing some of the writing of the literary critic Barbara Johnson on uncanny topics such as prosopopoeia, monuments and repetition. At stake here in particular is Johnson's unsettling contention that teaching concerns the repetition of what we do not yet understand (Johnson 1982), and her idea of "the thingliness of persons" (Johnson 2008). Already some monstrous quality may be making itself apparent: if the monster concerns crises in categories (see, for example, Cohen 1996; Mittman 2013; Steel 2013), then we perhaps detect its approach in the collapse of teaching into repetition, repetition into non-comprehension, and persons into things.

Our focus on Norwegian and English words, and literary critical concepts, means that this is a text concerning the relationship between monstrosity, culture and language, indebted to deconstructive approaches to texts (see e.g. Cohen 1996; Clark 1996; de Man 1986). Perhaps the most important coordinate here is Jacques Derrida's claim that "The future can only be anticipated in the form of an absolute danger. It is that which breaks absolutely with constituted normality and can only be proclaimed, presented, as a sort of monstrosity." (Derrida 1997, 5). Crucially, he connects this with writing - it is writing that opens the way to this future, writing that creates the future. One writes into the future and the future comes through writing. As we shall see, the present text concerns, in part, the dominance of English as a research language, so we might find an ethical imperative in this idea: that monsters allow us to make the space for new kinds of writing, new languages of thought. Monstrosity, and monstrous patterns meanings that are available in Norwegian rather than English - let slip alternative ways of thinking about teaching, writing and teaching writing. As Cohen says, "the monster always escapes" (Cohen 1996, 4).

A monster ${ }^{1}$ is a pattern, but its graphic similarity to "monster" is not a coincidence. Both words emerge from the Latin "monere," to warn or to instruct. Only in Norwegian can we understand the rich, uncanny inheritance of patterns, of monstre in a pattern there is a warning, an instruction, perhaps even a sense of threat. Or to put it another way - from warnings or instructions we derive patterns. But perhaps we can no longer remember those warnings, and as we repeat our patterns - of thinking, writing, teaching, what we repeat is something we do not fully understand.

The monsterlig is not a coherent category. If we try to translate monster in a way that lets through its monstrous Latin roots, it gathers together various possibilities of reading and interpretation which may overlap or even contradict each other. Here we might tune our ears to the secret alluded to in the title: I present here, then, not definitions but rather a set of language effects, the buried meanings that resonate when we hear "monster" or "monere" within "mønster":

- The concept of a pattern which emerges from warnings or instructions; we pattern only because we are warned or instructed; - A pattern whose history is forgotten, but which goes on repeating; such that I may be repeating what I do not understand; in everyday speech, the word monster functions without a sense of warning, so patterns may contain meanings that we have to recover; 
- A pattern or series of categories that warn of their own collapse, their own impossibility;

- Just as extracting "warning" from mønster creates the feeling of adding something to monster, the monsterlig is always in excess of itself - there is a monstrous surplus to it. There always seems to be too much monster, too much of the monsterlig. The monsterlig does not know where to stop.

Three ideas from Johnson, as we have touched on - prosopopoeia, monuments, and repetition - draw us into an understanding of the monsterlig. It is in some ways a fiction to separate them out - a monument, for example, is always connected with prosopopoeia, the voice of the dead; and simultaneously, a monument repeats, because it commemorates (or, perhaps, compels a reader or observer to repeat, to perform the commemoration). And, of course, knotting all of this together is the idea of the pattern, as to repeat is to create a pattern. All of these motifs tell us something about monstre. Drawing them together is the awful, impossible monster of becoming-thing - the way certain concepts of subjectivity pull us towards stone, inanimacy, thingness. As Johnson says, "deconstruction gravitate[s] to the inanimate: Paul de Man was happiest when proving that what we take to be human nature is an illusion produced by mechanical means" $(2008,4)$. She continues, discussing the figures of Pygmalion and Medusa:

a person turning to stone is usually bad, while a stone coming to life is usually desirable. But perhaps it is the confusion of the two realms that is really, and unavowedly, attractive. Walter Benjamin, in his study of the Paris arcades and the rise of commodity fetishism, speaks often of "the sex appeal of the inorganic" $(2008,20-21)$.

Taken with the figure of prosopopoeia which Johnson calls the "talking grave"
(2008, 14), a stone speaking - her work evinces both a fascination and a concern with category collapse, "and all the ways we already treat persons as things, and how humanness is mired in an inability to do otherwise" $(2008,2)$.

There is a second Nordic dimension to this discussion. This emerges from my own reflections as a teacher of English academic writing in Norway. As many commentators have observed (for example Canagarajah 2003; Pennycook 1994; Benesch 2009; Bennett 2014), this is not a neutral activity. Questions of power are in play when we talk about an academic lingua franca, because using the lingua franca means choosing not to use - or being compelled not to use - one's own language (if it ever makes sense to think of a language as 'mine'). So across this text, a series of interruptions occurs - breaking its flow, pushing against it, interrogating it; breaking into the linear trajectory that characterizes the dominant form of the 'academic essay in English'. This is done out of a recognition that English academic discourse is itself a monster, and finding the warnings that lie within it may interrupt it. English academic discourse can look monolithic, can appear essential, but it has a history and its epistemologic procedures are the result of specific cultural circumstances. The breaches in the present text are reminders that this discourse has limits, and that we can step outside, across and above them.

\section{Prosopopoeia}

Prosopopoeia is the rhetorical figure that means the speech of the voice of the something absent, the dead, speech from beyond the grave. In her discussion of epitaphs, Johnson also figures the 'talking grave' as a warning - which gives us the suggestion that prosopopoeia is mønsterlig. It is a category, a pattern, activated by a warning from within. The "deceased is animated ... only to warn the traveler of mor- 
tality - the corpse speaks, but only of death", says Johnson $(2008,14)$. But as our subject here is category collapse, of patterns that are impossible or in excess of themselves, the image of the 'talking grave' reveals that the patterns, or oppositions, that are collapsing are not only those between life and death, but also those between flesh and stone.

Of course, there are those who will try to stop this - who will say, "This is insupportable, patterns and categories must be preserved, this must cease" - another kind of warning. In her discussion of monsters and autobiography, Johnson thinks about Shelley's Frankenstein as a kind of autobiography - the mode of autobiography, of playing with selfhood as a species of monster, that is left to a woman writer because the alternative is the "humanistic tradition in which man is the measure of all things" (Johnson 2014a, 182). The idea of monstrosity as a mode of creativity that overruns the limits of a patriarchal humanism is echoed in her comment that "humanism is a strategy to stop reading when the text stops saying what it ought to have said" (Johnson 2014b, 347). In both cases, humanism is a kind of containment device, and whatever is outside the human (indeed, the masculine), must by definition be monstrous. There is a correspondence here with patterns: some are acceptable, and some are not. Humanism warns of monstrosity: "No, do not exceed this pattern, the text has now said what it was meant to say". Mønstre are always in excess of themselves, monstrous patterns that carry us over the limits of sense, of the oppositions that are the building blocks of Western philosophy, into what is impossible to be thought. This excess means that persons have a "thingliness" (Johnson 2008, passim) and can always be treated as things. The category 'person' ends up containing the category 'thing', and vice versa - and graves talk, stones speak.

One way of thinking about this crumbling opposition of flesh and stone leads us into Freud's exclamation "saxa loquuntur!" - stones speak! This is one of the archaeological metaphors Freud uses for the process of psychoanalysis, in which the remnants of a lost civilsation might be interpreted in the present:

Imagine that an employer arrives in a littleknown region where his interest is aroused by an expanse of ruins, with remains of walls, fragments of columns, and tablets with halfeffaced and unreadable inscriptions. (...) he may start upon the ruins, clear away the rubbish, and, beginning with the visible remains, uncover what is buried. If his work is crowned with success, the results are self-explanatory: the ruined walls are part of the ramparts of a palace or a treasure house; the fragments of columns can be filled out into a temple; the numerous inscriptions, which, by good luck, may be bilingual, reveal an alphabet and a language, and, when they have been deciphered and translated, yield undreamed-of information about the events of the remote past, to commemorate which the monuments were built. Saxa loquuntur! (Freud 1962, 192.)

\section{Interruption \# 1}

What happens to local research cultures when the pressure to publish internationally is brought to bear on them? How does one carve out space for regional concerns when, precisely, institutional structures do not reward such a focus? Does the injunction to publish 
internationally mean that regional research languages and topics are neglected? In such a willful, or willed, withering would there not be something monstrous? These are not new questions, of course. Twenty years ago, John Swales published an article called "English as Tyrannosaurus Rex" in which he grappled with the idea of English as "a powerful carnivore gobbling up the other denizens of the academic linguistic grazing grounds" (Swales 1997, 374). He is influenced here by Anna Mauranen, who - writing in 1993, at least - saw Finnish academic writing as distinctly different from English. Mauranen sees the level of metatext - the language that explicitly organises a text for a reader - in Anglo-American research articles as "reminiscent of another genre - marketing discourse" (Mauranen 1993a, 16). "The main thesis", she says, "is pointed out repeatedly, so as not to be missed", which, she argues, is an instance of "marketing type rhetorical strategies". Finnish academic discourses, on the other hand, have an "implicit, poetic" dimension (ibid., 17), whereby things are not spelled out in the same way. It is not that Mauranen thinks that one approach is better than the other, necessarily; but the dominance of English troubles her, as would the dominance of any language.

This could be thought of as a kind of prosopopoeia. These speaking stones of Freud correspond with the talking graves Johnson discusses: (...) "Prosopopoeia does not create a mouth ... so much as reanimate one; rhetorically, the dead come alive and the talking grave reverses the progress towards death" (Johnson 2008, 14). But this confusion of life and death, speech and stone, the animate and inanimate, also opens for Johnson another confusion, another monstrosity: the asymptotic relation between things and persons" is haunted by "the difficulty in being sure that we treat persons as persons" (Johnson 2008, 2). Our relations to others, in other words, always have something to do with prosopopoeia, with monstre. They trouble the belief that "one knows how people act, when in fact those beliefs may inhere in a linguistic system of which its users are not conscious" (Johnson 2008, 4). This brings us to the work of Catherine Malabou, and the idea of destructive plasticity. Malabou's philosophy, informed by neuroscience as well as psychoanalysis, unravels the opposition be- tween creation and destruction, collapsing pattern into monster. She imagines the plasticity of self that allows growth and creativity as being open, too, to destruction and accident. The mind and body's openness to accident is a component of self's plasticity, so that one can say, in monstrous - mønsterlig - fashion that destruction is formative. "What do we look like", she asks, "once we are formed by destructive, explosive, nuclear plasticity?" What becomes of a face, through age or accident, right before themoment before death?

How do we look? However beautiful and decisive, we have rejected the figures of trees, animals, and the fantastic beings described by Ovid. We no longer look like anything living, but nor do we look inanimate. We must imagine something between the animate and the inanimate, something that is not animate but has none of the inertia of stone, either. The inanimal? A between, or an instance that in no way resembles any intermediary, one that explodes mediations, outside the soul, outside the organic (Malabou 2016, 70-71). 
Malabou grapples here with the monstrous paradox of her premise - that destruction can be formative, that the self's plasticity can receive accident, that accident is therefore essential. These are premises beyond humanism, beyond 'what the text ought to say'. Outside this, there is the monster of the inanimal, being neither flesh nor stone and so taking the properties of both, becoming a kind of prosopopoeia. But there is more to it than this. As Johnson says, tion of the animate, 'that the living are struck dumb, frozen in their own death" (Johnson 2008, 39). No reading, therefore, without prosopopoeia, and without finding ourselves caught between flesh and stone. This is perhaps the real warning of the 'talking graves', the warning that lurks, monstrously or mønsterlig, forgotten, inside that particular rhetorical figure. As Nicholas Royle puts it, "We are ourselves spoken by skulls and spirits" (Royle 2003, 281).

\section{Interruption \#2}

Elsewhere, Mauranen writes:

Insofar as diversity provides a fruitful basis for innovation, we should encourage the maintenance of smallish, local academic communities with their own discourse and rhetorical practices. They should be maintained as cultural rainforests, in order to preserve the possibility of an original contribution to the common pool of scientific thought. Thus, insofar as rhetorical practices embody thought patterns, we should encourage the maintenance of variety and diversity in academic rhetorical patterns - excessive standardisation may counteract innovation and creative thought by forcing them into standard forms (Mauranen 1993b, 172).

This, perhaps, opens up a role for monstrosity in academic writing, particularly academic writing in English - one might seek new forms that contribute to this ecosystem, promote new kinds of knowledge or new experiences of understanding. One might seek to subvert the expected patterns of the dominant discourse.

prosopopoeia can function as a kind of general condition of reading: "People who want to summarise Of Grammatology try to explain what Derrida 'says"' (Johnson $2008,14)$. But a text is, precisely, not animate; a text does not say, or speak. So the figure of prosopopoeia carries a risk, a warning: as Johnson says, recalling Paul de Man, "there is a latent threat in any anima-

\section{Monuments}

As we saw earlier, Freud's the occasion of Freud's exclamation "stones speak!" is the discovery of "monuments". When we begin speaking about monuments, we are already talking about repetition (and this psychoanalytic context gives us another valence to Johnson's remark about repetition and understanding - the patient who seeks 
analysis is almost by definition enmeshed in structures of repetition they cannot understand). A monument compels us to repeat, to re-imagine, to commemorate. No monument without repetition, we might say. But we are also in the realm of prosopopoeia, because, as Johnson observes, a monument is another word for tombstone (Johnson 2008, 35). As we shall see, speaking of monuments is a task for an archaeologist, but perhaps an excessive task, a monstrous one.

If prosopopoeia means becoming stone, perhaps becoming oneself a monument, one might experience the physical sensation of "the angular cut of a shattered word" in one's mouth, against the tongue (Derrida 1986, xlviii) - as though a word is a thing. This uncanny quality of monumentalisation is built into Jacques Derrida's essay Fors, but translation opens another dimension of this - because we ascribe these words ("the angular cut of a shattered word") to Derrida, but they are in fact Barbara Johnson's. She is the translator of this particular essay, Fors. And elsewhere, talking about translations of Walter Benjamin, she refers to what an English translator "has Benjamin (...) say" (Johnson 2014c, 385), indicating the curious intimacy of translator and translated. The referencing conventions we use efface Johnson and preserve Derrida, but these are nonetheless Johnson's English words. 'Johnson' is present in 'Derrida'. Prosopopoeia again - who is animating whom?

Fors is a commentary by Derrida (and Johnson) on Abraham and Torok's reopening of Freud's "Wolf Man" case. For Derrida and Johnson, part of the value of Abraham and Torok's work is that it enacts the way theories of subjectivity must also carry with them something cryptic, something that is outside the subject (and the theory) but contained within it. Hence, the crypt is a kind of 'artificial unconscious', something both inside and outside the self:
Caulked or padded along its inner partition, with cement or concrete on the other side, the cryptic safe protects from the outside the very secret of its clandestine inclusion or internal exclusion. Is this strange space hermetically sealed? The fact that one must always answer yes and no to this question that I am deferring here will have already been apparent from the topographical structure of the crypt, on its highest level of generality: the crypt can constitute its secret only by means of its division, its fracture. "I" can save an inner safe only by putting it inside "myself," beside(s) myself, outside (Derrida 1986, xvi).

No theory of subjectivity, then, without a passenger, without someone repeating alongside me. To be an automaton, or to be an automaton's passenger - this is not only the psychoanalytic logic of the uncanny, but also of the crypt. I am here, but something else is here too, running its program, repeating and repeating. Again, this brings us back to the figure of prosopopoeia: indeed, it begins to turn it inside out. If I always carry a passenger, and this passenger is always hidden within my repetitions - without my ever understanding it - prosopopoeia becomes not merely the voice of the dead, but a kind of general condition of speaking and thinking at all. Prosopopoeia is with me when I speak, or teach; something else is always animating my words, present alongside me. "And then I can feel on the tip of my tongue", Derrida writes, "the angular cut of a shattered word."

This eruptive sentence is part of a passage that is more than usually hallucinatory, uncanny:

Striking demonstration of Crytptonomy: the crack in the symbol, the upright column of a name, for example, or the blank voice of a scruple, always extends out on the other side, beyond the self.

I am thinking (detached illusion) of the palaeontologist standing motionless, sudden- 
ly, in the sun, bewitched by the delicate stay of a word-thing, an abandoned stone instrument, like a tombstone burning in the grass, the double-edged stare of a two-faced Medusa.

And then I can feel, on the tip of my tongue, the angular cut of a shattered word.

What are we to do with this mysterious text? We began with the threatening feeling that flesh and stone, the animate and inanimate, might collapse into one another, and here it happens: we find, in our own mouths, words that have become stones, tombstones, things. It manifests a symbol, first, as a physical thing: something that may contain a crack. We have seen that it does the same thing with a word - a thing that can be shattered, angular. And again a name can be an upright column, as one might find at the site of a classical ruin. But the column at the same time is not upright - it "extends out on the other side" as though it has fallen. At the same time: "out of the other side" of what? Of me? The impossibility of parsing the topology here means it begins to resemble another impossible site: Freud's image of Rome, all the eras of its construction rising impossibly through one another, as a model for the preservative dimension of the unconscious (Freud 1991, 79). The contradictory topography, the outside made inside and death of all space, comes to an apotheosis in the phrase we began with: on the tip of his tongue, Derrida feels this angular cut of a shattered word. Where is the cut? Is it that a cut has occurred on his tongue, or is occurring at this moment? Or: do we follow the genitive, and see the cut as somehow the property of the shattered word - a cut that has occurred in the materiality of the word? Is the cut the pressure of the shattered word's sharp edges? And why on the tip of the tongue, this phrase that means the uncanny sensation of being about - of needing - to say something that you cannot quite remember?

And then: a "word-thing" that is also a stone, both an abandoned stone instrument and a tombstone. Again, this creates a kind of inescapable pressure in the text: there is no way to know what a stone instrument might be, or if an instrument can be stone. One could never know what purpose it might have, if it were a compass or a sextant, and whether a stone compass or sextant could ever be used, could ever actually be an instrument. Or, were it another kind of instrument, what music might be struck from it.

To follow through the strange, sundered logic of this text, and its relationship to teaching and repetition, we need to focus on an apparently insignificant detail. First, we might note, that when Derrida says "detached illusion", he means that it is an illusion that he and the motionless palaeontologist are separate. The logic of the crypt means that he both is and is not this other. To think of them as separate is, precisely, illusory. But more importantly - why "sun"? No doubt in part because it is one element in the Verbarium that Abraham and Torok construct from the Wolf Man's speech. But also because it repeats the experience of someone quite close in quarries and fascinations, to the palaeontologist - the archaeologist.

\section{Interruption \#3}

A further step is taken by Karen Bennett, who observes a continuity of style across what she calls English Academic Discourse (EAD), from the physical sciences to the humanities, but 
seeks also to complicate it. Discussing a textbook by Bryan Greetham (2008), How to Write Better Essays, she dryly points out that "he uses an interesting authority to support his call for clarity, conciseness and economy", the hallmarks of plain style. Greetham ties these virtues back to "what the Reverend Samuel Wesley once described as "the dress of thought: a modest dress, neat but not gaudy"'. Bennett comments:

Here, finally, we find an oblique reference to the historical origins of English writing style. For, as this brief quotation suggests, the virtues that it encapsulates are above all Protestant virtues - virtues which are manifested not only textually, but in all aspects of life, from dress taste and social style to financial habits. Hence, Greetham has unwittingly undermined the absolute claims made by most of the other authors in this survey. In highlighting the historic roots of the English taste in written style, he emphasises its culturally contingent nature, thereby leaving the door open for the affirmation of other styles which, owing to a diverging historical trajectory, may embody qualities that are entirely different (Bennett 2009, 53).

If, indeed, these virtues are historically determined, perhaps it is the duty of the writing teacher to encourage students to interrogate them, think beyond them, change them.

Freud is present, if that is the right word, in this passage too, at once sundering it and structuring it. It is the archaeologist Freud, the collector of antiquities, who is, as Derrida puts it in Archive Fever, "this brother to Hanold," comparing him to the protagonist of Jensen's Gradiva (Derrida 1998, 92), because of his love of archaeological metaphors. Saxa loquuntur - stones speak. Such is Freud's metaphor for a successful analysis. But here, something stranger is going on - Freud's analogy is being somehow de-analogised in Derrida's text so that words become things, stones become words. And then, there is the presence of the sun - Derrida "motionless in the sun, bewitched by the stay of a delicate wordthing" - this brings Hanold much more clearly into view, because Hanold's delusion - of Gradiva - takes as its element the sunlight. Gradiva is the "noonday ghost,"
Jensen $(1918,57)$ tells us, and sunlight always accompanies her appearance. So this combination of monuments means that Derrida repeats Hanold as well as Freud, and in doing so, teaches us what he does not understand. But what is this? The succession of references in Gradiva that that describe Hanold's solar delusion work their way forward into Derrida / Johnson's text. They repeat them, and something else becomes present in this repetition. And, let us not forget, Derrida / Johnson are teachers who repeat unconsciously the experience of a (fictional) teacher, as Hanold holds the university position of docent. The "detached illusion" in the sun, the sunstruck contemplations of a palaeontologist who is really an archaeologist, bend Derrida's (Johnson's) text into their path. There is a trace of this also in Derrida's note at the end of Archive Fever, that he is writing “on 
the rim of Vesuvius" (Derrida 1998, 97). This remark can also be thought of as placing him in the role of "brother to Hanold" - repeating Freud, repeating Jensen.

And Freud, too, describes an experience in the sun that is deranged, hallucinatory. An experience that also takes place in an Italian town. Freud is explicit that this is an experience of repetition, although it cannot be. It is, perhaps, though, an instance of the monsterlig, that paranoid, pattern-seeking faculty. Freud writes:

[Repetition] does undoubtedly, subject to certain conditions and combined with certain circumstances, arouse an uncanny feeling, which, furthermore, recalls the helplessness experienced in some dream-states.(...) I was walking, one hot summer afternoon, through the deserted streets of a provincial town in Italy (...) I found myself in a quarter of whose character I could not long remain in doubt. (...) I hastened to leave the narrow street at the next turning. But after having wandered about for a time without enquiring my way, I suddenly found myself back in the same street, where my presence was now beginning to excite attention. I hurried away once more, only to arrive by another détour at the same place yet a third time. Now, however, a feeling came over me that I can only describe as uncanny (...) (Freud 1955, 237).

This is no doubt uncanny. But is it repetitious? Surely a town cannot repeat? And yet - stones speak. Derrida repeats, transmits these repetitions from Jensen and Freud. And in the repetition they thicken, become thing-like. Everything congeals in repetition.

The perverse remembering that animates Derrida's (Johnson's) text here returns us to the idea of the monument. Cryptonomy, like all mourning, is a form of remembrance, memorialization or monumentalisation. And here, in its becoming-stone, it steers towards the threat of inanimacy that Johnson recalls from de Man. "A monu- ment, then", she writes, “is supposed to confer on memory the immortality that only inanimate things can possess. It seeks (... ) to honour something mere living memory might forget, or something that demands a collective, not individual, response" (Johnson 2008, 39). But "the durability and decontextualisation involved in canonical art" is precisely what may endanger the memory of what is preserved art travels from context to context, interpretation to interpretation. This process of recontextualisation and reinterpretation animates. But preserved inside the monument, its secret, is the desire to reach out to the observer and confer its memory perfectly, to activate the stony, prosopopoeic recesses of the soul, and enjoin the observer to become stone altogether.

\section{REPETITION COMPULSION}

If prosopopoeia is the voice of something absent, the voice of something dead, this may be what lies behind Johnson's idea that teaching is the repetition of what we do not yet understand. We do not understand whatever it is that haunts us as we speak to students in a classroom, and we are unaware of what lies behind the repeated patterns of our speech, these monstre.

Nicholas Royle follows through Johnson's idea with the feeling of disgust in teaching. Recalling Freud's observations that there is something uncanny in "impression of automatic, mechanical processes at work behind the ordinary appearance of mental activity" and in "Whatever reminds us of this inner 'compulsion to repeat'", Royle goes on to talk about the disgusting - we might say monstrous - feelings that occur with the dependence in teaching on repetition:

Teaching, and indeed even talking about teaching, can seem quite disgusting. So-called theories of education have perhaps taken insufficient account of such disgust. There is 
something disgusting, incipiently uncanny, perhaps, about the experience of repetition in talking to students, in memorizing or trying to memorize their names, in finding oneself seeming to say or being on the verge of saying exactly the same thing as one did an hour, or a day, or a year before (Royle 2003, 61$62)$.

Appropriately for a chapter on teaching and the uncanny, there is a psychoanalytic logic to this - it is not just that Royle repeats, but that one 'finds oneself' in the process of repetition. A sense of blankness, of depersonalization, passes through both the pronoun and the verb - 'oneself' (I am talking about myself, but have now bleached myself out with the use of this generalized pronoun), and 'finds' (I did not choose to do this, I have suddenly realized I am running a program, something is talking while I am merely a passenger). He brings this observation into contact with the remark from Johnson that we started with - the idea that "teaching is a compulsion: a compulsion to repeat what one has not yet understood" (1982, v). Perhaps some of this disgust, then, encodes the fear that one - I - will never understand; that what haunts my repetition, what secretly structures it, what cannot be found in it, will never be something that 'one' / 'I' understand(s).

In this repeating, or being on the verge of repeating - it is as though something is on the tip of one's tongue -

When Johnson starts working with this idea, she is compelled by one of the concluding stanzas of Coleridge's Ancient Mariner:

I pass, like night, from land to land;

I have strange power of speech;

That moment that his face I see,

I know the man that must hear me:

To him my tale I teach (Coleridge 2000, 437).

Johnson notes that the poem and the gloss it includes "disagree slightly over the nature of the act to teaching they describe. While in the gloss the mariner 'teaches (...) love and reverence,' in the poem he teaches only his "tale"". She goes on to argue that the gloss's didactic quality, then, "stands for a pedagogy that would repress the very stuff literature is made of" (Johnson 1982, $\mathrm{v})$. A "reading of the mariner himself", on the other hand, "would suggest that teaching is a compulsion: a compulsion to repeat what one has not yet understood".

\section{interruption \#4}

Bennett's work puts the construction of EAD into a historical context. She elaborates on her experiences as a translator between English and Portuguese, describing the tension between the rich, poetic, grammatically complex prose of Portuguese humanities writing, and the pre-existing shapes of EAD she must contort it into in translation. But there is also the implication in her work that EAD has in some sense colonized itself, in the way the positivist, empiricist language of the scientific revolution spread to other disciplines. She writes:

With the growing status of the natural sciences, the new kind of impersonal discourse acquired prestige and began to spread to other areas. Its associations with the bourgeoisie, which in the 17 th century was the social class in the ascendancy, also linked it firmly to 
the structures of wealth and power in the new social configuration. Thus began the process of colonization of other disciplines, beginning with the social sciences ... and moving on to all areas of knowledge in western society, even to less tangible domains like literature and art criticism (Bennett 2007, 160).

She continues, describing a survey she conducted among academic staff about their use of English:

One sociologist was particularly damning: "English discourse is impoverished and dogmatic. The questions raised at the outset are simplistic, and formulated in such a way as to require a YES/NO type of response, based upon mathematical models that tell us very little about reality. This is how they legitimize their science, grounding it in the logic of positivism" (Bennett 2007, 164).

But what might it mean to teach a tale? When the wedding guest, and all the others who have been taught this tale, recall it, what are they recalling? Johnson, observing the discontinuity between the poem and the gloss, discounts the idea that the mariner teaches a moral. The gloss suppresses the stuff of literature, she says, and the poem teaches instead ... what? The mariner teaches a tale - but what is the response of the student? The mariner does not merely explain his tale, or recount it he teaches it. And yet it seems unsatisfactory to say that he teaches the gist, the facts of it. Surely this would be too close to the gloss, and not really teaching at all, therefore. I find myself left with the uncanny feeling that the mariner teaches the poem, that is, the poem word for word - his "strange power of speech" is the power to inculcate repetition, to pass on exactly that strange power of speech. To teach, in other words, repetition. To teach a listener, to compel a listener, to repeat the poem. To make the listener him. It returns us to the idea that prosopopoeia is a general condition of reading and thinking, or being - I am always something other than myself. In this, it also returns us to the monstrous mode of autobiography that Johnson talks about - to talk about myself exceeds the limits of humanist reading. I am, impossibly, not me and me at the same time. Such is the mønster of autobiography, its mønsterlig perversions and compulsions.

There is, perhaps, another level to this too, directly connected with the disgust Royle mentions. The compulsion to repeat what one has not understood sounds like the monstrous itself - a conjoining of two things that are antithetical, the meaning and the meaningless. How much knowledge, unconscious and undreamt of, and at the same time on the tip of the teacher's tongue, is encrypted in this strange scene? How can one repeat what one has not yet understood - not only not understood but not known, not experienced, not encountered? How can one repeat what has not yet come to light? Or, to put it another way 


\section{Interruption \#5}

A. Suresh Canagarajah discuss the idea of code-switching in a language-learning context, whereby language learners can benefit from moving between languages as they speak (Canagarajah 2003, 131). Perhaps there is scope to adapt this idea, to bring, for example, Norwegian or other Nordic words into English. Mauranen suggests that Finnish patterns of thought might be preserved even when writing in English; but perhaps English writers, too, can seek out the habits of thought and speech that characterize other scholarly cultures. I have been thinking, alongside these remarks, of the Norwegian words that translate prosopopoeia - personifikasjon (personification) and besjeling (giving soul to - literally, ensoulment). The idea that to be given personhood, and soul, are different is something I find compelling and fascinating, and I wonder if it tells us something more about the mønsterlig dimensions of prosopopoeia we have been discussing.

- what else can one repeat?

The teacher cannot perceive the monsterlig, what is behind the patterns of his or her speech. It is only another, an other, who can do that work. Royle's disgust might be further understood if we place it alongside another remark from Derrida, one of his most well-known evocations of the monster:

the future is necessarily monstrous: the figure of the future, that is, that which can only be surprising, that for which we are not prepared, you see, is heralded by species of monsters. A future that would not be monstrous would not be a future; it would already be a predictable, calculable, and programmable tomorrow. All experience open to the future is prepared or prepares itself to welcome the monstrous arrivant (Derrida 1995b, 386387.)

This, then, some essence of the monsterlig - it is disgusting, to be sure, the repetition nauseates me, but this is in part because it is of the other and for the other. There is always a passenger, a crypt, in my repetition. But I will never know the secret of it - I will never understand the pattern. That is the work of another, perhaps, indeed, a student. So the repetition opens into the future. It is on the tip of the tongue, and someone, unbeknownst to me, in my future, may hear this, may hear whatever it is that is encoded inside or onto monstrene. And be therefore a party to and recipient of the revelation I can never bear witness to.

\section{Final Interruption}

Perhaps, over the course of these remarks about predatory discourses, the reader has thought, "Well, why didn't you do ..." or "couldn't you have ..." or "Could you not have written ..." Perhaps I could have; perhaps I was unable to; perhaps I will be able to try, next time. But if you have felt that these interruptions do not push forcefully enough, do 
not exert enough pressure, perhaps, precisely, they have done what they need to do for now. The work of the writers described in these interruptions - or to borrow and adapt a term from Bennett, this semi-periphery - should encourage and enjoin us to seek styles and approaches that interrupt, that create problems, category mistakes, collapsing concepts, monstre.

\section{CONCLUDING REMARKS}

The mønsterlig, we said at the beginning, is not a coherent category. How could it be? Too many things are released from the combination of mønster and its Latin origin (again, the excess - adding the origin to the present) for the monster's warnings to be coherent. Over the course of this discussion, we have been thinking about the way the uniqueness of the Norwegian word mønster gives us an opportunity to think about the monstrous in other languages and other contexts, too. Because of its excessiveness, its uncanny supplementarity, it demands that we look for collapsing categories, for flesh becoming stone, repetition becoming thing. The monster warns that we cannot hold these categories separate. And not least when they concern the future. We have always been heading to this point, perhaps - that to talk about the monster we would have to talk about the future, because the future is opened by a warning. One future, at any rate. But even in this, we are at risk of category collapse. If someone comes after the teacher who can attend to their patterns more clearly, detect in them whatever was not understood in the present, then that teacher, perhaps, is becoming monument, stone, and that stone is reaching out to the student.

\section{Notes}

1. Plural forms: mønstre $=$ patterns; mønstrene $=$ the patterns. I also suggest here the coinage mønsterlig as an adjective - the monstrously patterned. 2. What would the work of Freud look like without literature? Freud's Delusion and Dream in Jensen's Gradiva (1959) is an analysis of Wilhelm Jensen's ghost story Gradiva, in which Norbert Hanold, a young archaeologist and docent, travels to Pompeii and is haunted by a "noonday ghost" among the ruins. Freud's reading is itself the subject of an analysis by Derrida in Archive Fever (1998), in which Derrida thinks about Freud's own fascination with archaeology and antiquity, and compares Freud to the protagonist of Gradiva.

\section{REFERENCES}

- Benesch, S. 2009. Critical English for Academic Purposes: Theory, Politics and Practice. New York: Routledge.

- Bennett, K. 2007. Epistemicide!: The Tale of a Predatory Discourse. The Translator 13 (2), 151 169.

- Bennett, K. 2009. English Academic Style Manuals: A Survey. Journal of English for Academic Purposes 8 (1), $43-54$.

- Bennett, K. 2014. The Semiperiphery of Academic Writing: Discourses, Communities and Practises. Houndmills, Basingstoke: Palgrave Macmillan. - Canagarajah, A. Suresh. 2003. Resisting Linguistic Imperialism in English Teaching. Oxford: Oxford UP.

. Clark, D.L. 1996. Monstrosity, Illegibility, Denegation: De Man, bp Nichol and the Resistance to Postmodernism. In: Cohen, J.J. ed. Monster Theory: Reading Culture. Minneapolis: Minnesota UP, 40-71.

- Cohen, J.J. 1996. Monster Culture (Seven Theses). In: Cohen, J.J. ed. Monster Theory: Reading Culture. Minneapolis: Minnesota UP, $3-25$. 
. Coleridge, Samuel Taylor. 2000. The Rime of the Ancient Mariner. In: Abrams, M.H., Greenblatt, S. et al (eds.), The Norton Anthology of English Literature, vol. 2 ( $7^{\text {th }}$ ed.) New York: Norton.

- De Man, P. 1986. The Resistance to Theory. Minneapolis: Minnesota UP.

- Derrida, J. 1986. Fors: The Anglish Words of Nicolas Abraham and Maria Torok. Trans. Johnson, B. Introduction to Abraham, N. and Torok, M. The Wolf Man's Magic Word: A Cryptonomy. Minneapolis: Minnesota UP, xi-xlviii.

- Derrida, J. 1995. Passages - from Traumatism to the Promise. Trans. Kamuf, P. In: Points ... Interviews, 1974 - 1994. Stanford: Stanford UP, $372-$ 395.

- Derrida, J. 1997. Of Grammatology. Trans. Spivak, G. Baltimore: Johns Hopkins UP.

- Derrida, J. 1998. Archive Fever: A Freudian Impression. Trans. Prenowitz, E. Chicago: Chicago UP.

. Freud, S. 1955. The "Uncanny." Trans. Strachey, J. In: The Standard Edition of the Complete Psychological Works of Sigmund Freud, vol. XVII. London: Hogarth Press, 217 - 252.

- Freud, S. 1959. Delusions and Dreams in Jensen's Gradiva. Trans. Strachey, J. In: The Standard Edition of the Complete Psychological Works of Sigmund Freud, vol. IX. London: Hogarth Press, 7-93.

. Freud, S. 1962. The Aetiology of Hysteria. Trans. Strachey, J. In: The Standard Edition of the Complete Psychological Works of Sigmund Freud, vol. III. London: Hogarth Press, $187-221$.

- Greetham, B. 2008. How to Write Better Essays. Houndmills, Basingstoke: Palgrave Macmillan.

- Jensen, W. 1918. Gradiva: A Pompeiian Fantasy. Trans. Downey, H. New York: Moffat, Yard. - Johnson, B. 1982. Teaching as a Literary Genre. Yale French Studies 63, iii - vii. - Johnson, B. 2008. Persons and Things. Cambridge, MA: Harvard UP.
- Johnson, B. 2014a. My Monster, My Self. In: The Barbara Johnson Reader: The Surprise of Otherness. Durham, NC: Duke UP, 179-190.

- Johnson, B. 2014b. Teaching Deconstructively. In: The Barbara Johnson Reader: The Surprise of Otherness, 347-356.

- Johnson, B. 2014c. The Task of the Translator. In: The Barbara Johnson Reader: The Surprise of Otherness, 377-400.

- Malabou, C. 2016. Ontology of the Accident: An Essay on Destructive Plasticity. Trans. Shread, C. Cambridge: Polity.

- Mauranen, A. 1993a. Contrastive ESP Rhetoric: Metatext in Finnish-English Economics Texts. English for Specific Purposes 12, 3-22.

- Mauranen, A. 1993b. Cultural Differences in Academic Discourse - Problems of a Linguistic and Cultural Minority. In: Löfman, L. et al. eds. The Competent Intercultural Communicator. Helsinki: AFinLa, 157 - 174.

- Mittman, A.S. 2013. Introduction: The Impact of Monsters and Monster Studies. In: Mittman, A.S., and Dendle, P.J. (eds.) The Ashgate Research Companion to Monsters and the Monstrous. Farnham, Surrey: Ashgate, 1-16.

- Pennycook, A. 1994. The Cultural Politics of English as an International Language. Harlow, Essex: Pearson.

- Royle, N. 2003. The Uncanny. Manchester: Manchester UP.

- Steel, K. 2013. Centaurs, Satyrs, and Cynocephali: Medieval Scholarly Teratology and the Question of the Human. In: Mittman, A.S., and Dendle, P.J. (eds.) The Ashgate Research Companion to Monsters and the Monstrous. Farnham, Surrey: Ashgate, 257-274.

- Swales, J. 1997. English as Tyrannosaurus Rex. World Englishes 16 (3), 373 - 382. 